\title{
Flowering of the Cover Crop Sunn Hemp, Crotalaria juncea $\mathrm{L}$.
}

Robert L. Meagher, Jr. ${ }^{2}$, Rodney N. Nagoshi, and James T. Brown ${ }^{1}$ Insect Behavior and Biocontrol Research Unit, USDA-ARS CMAVE, Gainesville, FL 32608

\author{
Shelby J. Fleischer \\ Department of Entomology, Pennsylvania State University, University Park, \\ $P A 16802$
}

John K. Westbrook
Insect Control and Cotton Disease Research Unit, USDA-ARS SPARC,
College Station, TX 77845-4966

Carlene A. Chase

Horticultural Sciences Department, University of Florida, 1253 Fifield Hall, Gainesville, FL 32611

Additional index words. seed production, sorghum-sudangrass

\begin{abstract}
Sunn hemp, Crotalaria juncea $\mathrm{L}$., is a warm-season legume that is planted before or after a vegetable cash crop to add nutrients and organic matter to the soil, for weedgrowth prevention, and to suppress nematode populations. Sunn hemp flowers may also provide nectar and pollen for pollinators and enhance biological control by furnishing habitat for natural enemies. Despite these benefits, adoption in the United States has been limited because of restricted availability of seeds, particularly in temperate climates. Experiments were conducted in north-central Florida to compare flowering and seed production of domestic and foreign sunn hemp lines across different seeding rates and planting dates. Our objectives were to test whether a low seeding rate would result in the production of higher numbers of flowers and to test whether planting earlier in the season would also result in higher numbers of flowers. Our results over a 2 year period showed that the domestic cultivar AU Golden is capable of substantial flowering and seed production in the test region, confirming the compatibility of local environmental conditions. Seed costs suggest that 'AU Golden' is comparable with sunn hemp lines grown in foreign countries and is much less expensive than the standard cultivar Tropic Sun from Hawaii. The results demonstrate the potential economic viability of early flowering cultivars of sunn hemp as a cover crop alternative in Florida to improve soils in agricultural landscapes.
\end{abstract}

Sunn hemp, Crotalaria juncea L., is a warm-season legume that is planted before or after a vegetable cash crop to add nutrients and organic matter to the soil (Cherr et al., 2006, 2007; Mansoer et al., 1997; Wang

Received for publication 31 Mar. 2017. Accepted for publication 18 May 2017.

We thank the staff at the University of Florida Plant Science Research and Education Center in Citra, FL for planting and management of the sunn hemp plots. We recognize the financial support of the National Institute of Food and Agriculture, U.S. Department of Agriculture, under Agreement No. 2011-67003-30209.

The use of trade, firm, or corporation names in this publication is for the information and convenience of the reader. Such use does not constitute an official endorsement or approval by the United States Department of Agriculture or the Agricultural Research Service of any product or service to the exclusion of others that may be suitable.

${ }^{1}$ Current address: Entomology and Nematology Department, University of Florida, 1881 Steinmetz Hall, Gainesville, FL 32611

${ }^{2}$ Corresponding author. E-mail: rob.meagher@ars. usda.gov. et al., 2005). This cover crop provides other benefits to growers such as suppression of weeds (Adler and Chase, 2007; Cho et al., 2015; Collins et al., 2008; Javaid et al., 2015; Morris et al., 2015; Mosjidis and Wehtje, 2011) and suppression of plant-parasitic nematode populations by not providing resources (Bhan et al., 2010; Braz et al., 2016). Sunn hemp is available to growers in northern Florida, where 10,000 ha of vegetables (potatoes, Solanum tuberosum L., and cabbage, Brassica oleracea L. var. capitata) are annually produced (Elwakil and Mossler, 2016; USDA-NASS, 2014).

A major advantage of sunn hemp over many cover crops, particularly sorghumsudangrass (SSG) [Sorghum bicolor (L.) Moench], is that it is a poor host for fall armyworm [Spodoptera frugiperda (J. E. Smith)] and other important moth pests (Meagher et al., 2004). Southern Florida is a major overwintering region for fall armyworm populations that annually migrate northward and infest corn acreages along the eastern United States. Sorghumsudangrass is one of the common cover crop and forage grasses in the United States and therefore is a likely source of fall armyworm populations (Meagher et al., 2004; Pair and Westbrook, 1995). Therefore, large scale replacement of SSG with sunn hemp in Florida could mitigate fall armyworm populations before and during these annual migrations on an area-wide scale.

Another ecological service that cover crops can provide is flowers that provision pollinators and enhance biological control (Campbell et al., 2016). Studies have shown that early season flowering by cover crops can increase pollinator populations, which promote late-season pollination in cash crops (Riedinger et al., 2014). Flower density and the richness of the cover crop plants have the most direct influence on bee visitation and native bee abundance (Ellis and Barbercheck, 2015; Saunders et al., 2013).

The first sunn hemp cultivar commercialized in the United States was 'Tropic Sun', which was a direct increase of the original seed purchased in 1958 from the island of Kauai, HI and developed by the USDA Natural Resources Conservation Service (NRCS) and the University of Hawaii College of Tropical Agriculture and Human Resources (CTAHR) as a cooperative release in 1983 (Rotar and Joy, 1983; later identified as developed from PI 468956, Wang et al., 2006). Seed production in the tropics is good; however, because of this cultivar's flowering response to short days, seed production is generally poor in the continental United States (Mosjidis, 2007; White and Haun, 1965). Therefore, seed availability to growers was limited to importation of 'Tropic Sun' from Hawaii or bringing in other germplasm from Brazil, India, South Africa, or other foreign locations. A breeding program to increase flowering and seed production was initiated at Auburn University in 2002. 'AU Golden' was developed from accession PI 322377, which was obtained from the National Plant Germplasm System. In a patent application, this germplasm was shown to be able to produce seed in Alabama, with the data extrapolated to indicate flower production, seed production, or both in the region between $40^{\circ}$ north and $40^{\circ}$ south latitude, and at least $400 \mathrm{lbs}$ seed per acre when grown between $28^{\circ}$ north and $28^{\circ}$ south latitude (Mosjidis, 2014). These characteristics make it a potentially useful cover crop for much of Florida, which lies between $25^{\circ}$ and $31^{\circ}$ north latitude. However, it is not clear whether the local environment, including such factors as soil type, disease, herbivores, and appropriate pollinators, is conducive to this line of sunn hemp.

To examine the potential and optimize sunn hemp cover crop usage in north-central Florida, multiple sunn hemp lines were tested in field studies to compare flowering and seed production across different seeding rates and planting dates. One objective was to test whether a low seeding rate would result in the production of higher numbers of flowers and seed pods. A second objective was to test whether planting 'AU Golden' earlier in the 
season would result in both higher numbers of flowers produced and, because we felt that there was more pollinator activity at this time of year, higher seed production. A final goal was to test whether similar sunn hemp seeding could be obtained but with the potential for higher overall biomass per acre if a mixture of sunn hemp and SSG was used as a cover crop.

\section{Materials and Methods}

Sunn hemp germplasm. Four different sunn hemp lines were used in the experiments. The two lines from the United States were 'Tropic Sun', purchased Mar. 2014 from Molokai Seed Co., Kaunakakai, HI, and 'AU Golden', purchased Mar. 2014 and Apr. 2015 from Petcher Seeds, Fruitdale, AL. The two foreign lines were Tillage Sunn (purchased Mar. 2014 from Hancock Seed Co., Dade City, FL), a brand of sunn hemp from India which is sold through several seed distributors, and an unknown germplasm (variety not stated) from South Africa (purchased Mar. 2011 from Petcher Seeds).

2014 trial. The experiment in 2014 was designed to compare flowering and seed production of four sunn hemp lines planted at three different seeding rates. Plots were arranged as a randomized complete block with three blocks, yielding 12 plots per block and a total of 36 plots. Sunn hemp plots were planted 23 Apr. 2014 at the University of Florida Plant Science Research and Education Unit, Citra, FL $\left(29^{\circ} 24^{\prime} 42^{\prime \prime} \mathrm{N}\right.$, $\left.82^{\circ} 06^{\prime} 36^{\prime \prime} \mathrm{W}\right)$. Seed densities were designed to replicate a low seeding rate for seed production $(11.2 \mathrm{~kg} / \mathrm{ha}=10 \mathrm{lbs} /$ acre $)$, a high seeding rate for use as a cover crop $(44.8 \mathrm{~kg} /$ $\mathrm{ha}=40 \mathrm{lbs} / \mathrm{acre}$ ), and a medium seeding rate $(28.0 \mathrm{~kg} / \mathrm{ha}=25 \mathrm{lbs} / \mathrm{acre})$ (Cho et al., 2015). Each plot was $3.66 \mathrm{~m} \times 7.62 \mathrm{~m}$, with a $1.83-\mathrm{m}$ unplanted border between plots. The 3 blocks were separated by $3.66 \mathrm{~m}$. Sunn hemp seed was mixed with a cowpea-type Rhizobium inoculum before planting and was broadcast by hand and then covered manually with rakes. Plots were irrigated with overhead irrigation throughout the season and a temperature monitoring system was located at the experiment station (Florida Automated Weather Network, University of Florida IFAS Extension, http://fawn.ifas.ufl.edu/). Temperatures averaged $23.7^{\circ} \mathrm{C}$ from March through September.

2015 trial. The experiment in 2015 was also conducted at Citra, FL. Of the four lines evaluated in 2014, only 'AU Golden' appeared capable of producing mature seed under north Florida conditions. Therefore, the 2015 trial was designed to compare seed production of 'AU Golden' when planted at three different times during the season and at two seeding rates. For growers wanting to use sunn hemp strictly as a cover crop and to obtain more plant biomass per area with the same amount of sunn hemp seed, SSG was added to the high and low seeding rates. Plots were planted on 27 Apr., 26 June, and 26 Aug. The randomized complete block experimental design contained three blocks and four treatments, sunn hemp at $11.2 \mathrm{~kg} / \mathrm{ha}$ (SH11), at $44.8 \mathrm{~kg} / \mathrm{ha}(\mathrm{SH} 44)$, at $11.2 \mathrm{~kg} / \mathrm{ha}$ plus SSG at $22.4 \mathrm{~kg} / \mathrm{ha}$ (SH11SSG), and at $44.8 \mathrm{~kg} / \mathrm{ha}$ plus $\mathrm{SSG}$ at $22.4 \mathrm{~kg} / \mathrm{ha}$ (SH44SSG). Each plot measured $7.6 \mathrm{~m} \times$ $33.8 \mathrm{~m}$, with $0.3 \mathrm{~m}$ between plots. Sunn hemp seed was mixed with a cowpea-type Rhizobium inoculum before planting and was broadcast by hand and then covered by a roller. Plots were irrigated with overhead irrigation throughout the season and temperatures averaged slightly higher during March through Sept. 2015 than in $2014\left(24.9^{\circ} \mathrm{C}\right)$.

Plant sampling. To provide a measure of reproductive potential, 10 randomly selected 'AU Golden' plants per plot were harvested and the number of racemes and "flowers" were counted on 11 July 2014. The category "flowers" included developing buds, open flowers, old flowers, and seed pods. The total number of seed pods was determined on 30 July 2014 from another set of 10 randomly selected plants per plot. The number of seeds per pod was counted from one randomly selected pod per plant. For yield estimation, 'AU Golden' plants that contained seed pods were counted on 25 Sept. 2014. Tillage Sunn flowers were counted using the same methods on 10 Sept. 2014. Because a large percentage of the reproductive parts were developing buds $(80.7 \% \pm 2.2 \%)$, number of seed pods and seeds per pod were not counted. 'Tropic Sun' and the line from South Africa produced only small numbers of flowers late in the season and were not included in the analyses.

In 2015, variables measured and compared among planting dates and seeding rate treatments were number of sunn hemp plants, number of plants with seed pods, number of seed pods, and number of seeds per pod. Plant count locations were randomized by throwing a projectile into each plot. A square meter quadrat was centered on the projectile, and all sunn hemp plants were counted. Three observations per plot were made for each treatment. Plant counts were made 10 June for the 27 Apr. planting, 13 Aug. for the 26 June planting, and 16 Oct. for the 26 Aug. planting.

'AU Golden' sunn hemp plants containing seed pods were counted 116 and $122 \mathrm{~d}$ after planting in April and June, respectively. Seed pod counts used the same randomization technique; however, only one observation was made per plot. Plants containing seed pods within the quadrat were removed from the plots, and the number of plants and seed pods was counted. The number of seeds in one randomly selected seed pod was also counted. Seed pod counts were made 21 Aug. for the 27 Apr. planting and 26 Oct. for the 26 June planting. Very few seed pods were produced in the 26 Aug. planting and, therefore, were not sampled.

Sunn hemp yield. Sunn hemp yield was calculated by multiplying the number of podbearing plants by the number of seed pods to get a measure of seed pods $/ \mathrm{m}^{2}$. This was multiplied by the mean number of seeds per pod and the average weight per seed. Finally seed pods $/ \mathrm{m}^{2}$ was multiplied by weight per pod to give yield per hectare.

Statistical analysis. All analyses were conducted using SAS (SAS 9.4, SAS Institute, 2012). All data were analyzed using Box-Cox (PROC TRANSREG) and PROC UNIVARIATE to find the optimal normalizing transformation (Osborne, 2010). Analysis of variance (PROC MIXED, LSMEANS with adjusted Tukey test) was then used to separate variable means. In 2014, only 'AU Golden' and Tillage Sunn flowered, but the time of sampling and flower development rate were different between the lines, therefore they were analyzed separately. Seeding rate (3) and block (3) were the fixed and random variables, respectively, in the models for raceme and flower. Only the number of 'AU Golden' plants, seed pods and seeds per pod were analyzed among seeding rates (3) and blocks (3). The 2015 plant count data were analyzed using a nested design in PROC MIXED, with planting date (3) and seeding rate treatment (4) as the fixed variables and block within seeding rate as the random variable. The 2015 seed plant data were analyzed with all data and separately for the 27 Apr. and 26 June planting dates using PROC MIXED, with seeding rate treatment (4) as the fixed variable and block (3) as the random variable.

\section{Results}

Flowering and seed production 2014. The different sunn hemp lines were compared for flowering and seed production. 'AU Golden' and Tillage Sunn produced substantially more flowers than 'Tropic Sun' and the line from South Africa, with the latter two showing only a few flowers very late in the season (October). The racemes from 'AU Golden' plots sampled $79 \mathrm{~d}$ after planting were composed predominately of seed pods $(57.9 \% \pm$ $2.3 \%)$, followed by developing buds $(23.4 \% \pm$ $1.3 \%)$, open flowers $(11.3 \% \pm 2.6 \%)$, and old flowers $(7.5 \% \pm 0.5 \%)$. The Tillage Sunn plots sampled $140 \mathrm{~d}$ from planting were composed primarily of developing buds $(80.7 \% \pm 2.2 \%)$, followed by old flowers $(8.8 \% \pm 1.2 \%)$, seed pods $(6.1 \% \pm 1.7 \%)$, and open flowers $(4.5 \% \pm 0.9 \%)$

The 'AU Golden' and Tillage Sunn lines were separately tested for effects of seeding rate on flowering and seed pod production. The low seeding rate plots of 'AU Golden' plants contained more racemes and flowers than both the medium and high seeding rate plots (Table 1). As expected, more 'AU Golden' plants containing seed pods were found in the high seeding rate plots compared with the medium and low seeding rate plots (Table 2). The low seeding rate plots contained higher numbers of seed pods per plant than the other two treatments; however, the number of seeds per pod was not different among seeding rates. Because the high seeding rate plots had more plants, yield was higher than in the low seeding rate plots (Table 2). In comparison, Tillage Sunn plants contained similar numbers of racemes and 
flowers across the seeding rate plots but produced few seed pods per plant, and the data were not analyzed.

Flowering and seed production 2015. In 2015, we retested 'AU Golden' at different

Table 1. Number of racemes (secondary branches) and flowers per plant (mean $\pm \mathrm{SE}$ ) for 'AU Golden' and Tillage Sunn plants sampled 79 and $140 \mathrm{~d}$ after planting, respectively. Sunn hemp was planted at low $(11.2 \mathrm{~kg} / \mathrm{ha})$, medium $(28.0 \mathrm{~kg} / \mathrm{ha})$, or high $(44.8 \mathrm{~kg} / \mathrm{ha})$ seeding rates, Citra, FL, 2014. Means within each variable and line followed by the same letter are not significantly different.

\begin{tabular}{|c|c|c|c|}
\hline Variable & Line & Seeding rate & Mean $\pm \mathrm{SE}$ \\
\hline \multirow[t]{5}{*}{ Racemes $^{z}$} & $\mathrm{AU}$ & Low & $26.8 \pm 0.9 \mathrm{a}$ \\
\hline & & Medium & $20.7 \pm 0.3 b$ \\
\hline & & High & $21.1 \pm 0.8 \mathrm{~b}$ \\
\hline & Tillage & Low & $50.4 \pm 1.9 \mathrm{a}$ \\
\hline & & $\begin{array}{l}\text { Medium } \\
\text { High }\end{array}$ & $\begin{array}{l}60.6 \pm 14.8 \mathrm{a} \\
43.8 \pm 5.4 \mathrm{a}\end{array}$ \\
\hline \multirow[t]{6}{*}{ Flowers $^{\mathrm{y}}$} & & Low & $166.9 \pm 8.1 \mathrm{a}$ \\
\hline & & Medium & $130.9 \pm 3.9 b$ \\
\hline & & High & $122.0 \pm 4.5 \mathrm{~b}$ \\
\hline & Tillage & Low & $181.7 \pm 8.8 \mathrm{a}$ \\
\hline & & Medium & $229.6 \pm 59.1 \mathrm{a}$ \\
\hline & & High & $188.4 \pm 40.7 \mathrm{a}$ \\
\hline \multicolumn{4}{|c|}{$\begin{array}{l}\text { 'Data were transformed using } \mathrm{Y}^{-1.5} \text {. 'AU Golden', } \\
F=26.4, \mathrm{df}=2,4, P=0.0050 ; \text { Tillage Sunn, } \\
F=0.44, \mathrm{df}=2,4, P=0.6719 . \\
F=25.2, \mathrm{df}=2,4, P=0.0054 ; \text {; Tillage Sunn, } \\
F=0.09, \mathrm{df}=2,4, P=0.914 .\end{array}$} \\
\hline
\end{tabular}

Table 2. Number of plants containing seed pods per $\mathrm{m}^{2}$, number of seed pods per plant, number of seeds per pod, and calculated yield $(\mathrm{kg} / \mathrm{ha})$ for 'AU Golden' plants sampled $98 \mathrm{~d}$ after planting. Sunn hemp was planted at low (11.2 $\mathrm{kg} / \mathrm{ha})$, medium $(28.0 \mathrm{~kg} / \mathrm{ha})$, or high $(44.8 \mathrm{~kg} /$ ha) seeding rates, Citra, FL, 2014. Means within each variable and seeding rate followed by the same letter are not significantly different.

\begin{tabular}{clc}
\hline Variable & Seeding rate & Mean \pm SE \\
\hline $\begin{array}{c}\text { Plants with } \\
\text { seed pods }\end{array}$ & Low & $6.1 \pm 0.4 \mathrm{c}$ \\
& Medium & $16.9 \pm 1.5 \mathrm{~b}$ \\
& High & $23.5 \pm 1.0 \mathrm{a}$ \\
Seed Pods & Low & $128.9 \pm 6.7 \mathrm{a}$ \\
per plant $^{\mathrm{y}}$ & & \\
& Medium & $71.7 \pm 1.8 \mathrm{~b}$ \\
& High & $71.7 \pm 1.2 \mathrm{~b}$ \\
Seeds/pod $^{\mathrm{x}}$ & Low & $9.53 \pm 0.41 \mathrm{a}$ \\
& Medium & $9.17 \pm 0.41 \mathrm{a}$ \\
& High & $9.6 \pm 0.058 \mathrm{a}$ \\
Yield $^{\mathrm{w}}$ & Low & $439.0 \pm 62.4 \mathrm{~b}$ \\
& Medium & $643.7 \pm 88.4 \mathrm{ab}$ \\
& High & $930.5 \pm 50.2 \mathrm{a}$ \\
\hline
\end{tabular}

${ }^{\mathrm{z}}$ Data were transformed using $\mathrm{Y}^{0.5}$. Plants per $\mathrm{m}^{2}$ with seed pods counted $155 \mathrm{~d}$ after planting; $F=$ $88.0, \mathrm{df}=2,4, P=0.0005$.

${ }^{\mathrm{y}}$ Data were transformed using $\mathrm{Y}^{0.75}$. Seed pods per plant counted $100 \mathrm{~d}$ after planting; $F=71.8 \mathrm{df}=2$, $4, P=0.0007$.

${ }^{\mathrm{x}}$ Data were transformed using $\mathrm{Y}^{0.75}$. Seeds per pod counted $100 \mathrm{~d}$ after planting; $F=0.5, \mathrm{df}=2,4, P=$ 0.6412 .

${ }^{\mathrm{w}}$ Data were transformed using $\mathrm{Y}^{0.5}$. Yield per kg; $F=9.2, \mathrm{df}=2,4, P=0.0320$. seeding rates while also examining the effects of two later seeding times (June and August) and the addition of SSG. As in 2014, sunn hemp plots planted at a high seeding rate contained more plants than all other treatments (SH44, 59.1 \pm 7.3). Unlike 2014, no significant differences were found in the number of plants containing seed pods at low (SH11) or high (SH44) seeding rates for either the April or June planting dates (Table 3). A mixed result was obtained for seed pods per plant, as the April planting showed no significant difference among seeding rates whereas in the June planting the low seeding rate was significantly higher than the high seeding rate treatment. The latter result is similar to what was observed in 2014. No differences among seeding rates were observed for seeds per pod or yield (Table 3 ).

The time of planting had substantial effects on the number of plants per area. When averaged across treatments, more plants per square meter were counted in plots planted in August $(35.4 \pm 4.7)$ than in plots planted in April (22.2 \pm 2.6$)$, whereas plots planted in June were intermediate and not different from
August or April-planted plots $(34.6 \pm 6.0)$ $(F=3.3, \mathrm{df}=2,24, P=0.0548$; adjusted Tukey test comparing means, $t=-2.56$, $\mathrm{df}=24, P=0.0436$ ). The average number of plants with seed pods was similar for the April and June plantings (April $22.6 \pm 5.5$, June $26.9 \pm 4.1 ; F=1.2, \mathrm{df}=1,17, P=0.2806)$, but plants planted in August did not produce seed pods before the end of the growing season. Even though there were similar numbers of seed pod-bearing plants in April and June, sunn hemp planted in April produced over 10 times more pods per plant than those planted in June $(41.8 \pm 7.2$ vs. $3.9 \pm 0.5$, respectively; $F=28.9, \mathrm{df}=1,17, P<0.0001$ ). Because sunn hemp planted in April contained more seed pods, the yield was also much higher than the June plants $(294.9 \pm 31.9$ vs $30.1 \pm 2.8$, respectively; $F=224.1, \mathrm{df}=1,17$, $P<0.0001)$. However, there was no treatment difference in yield in the April or June-planted plots (Table 3). Planting date also affected the number of seeds per pod, as April pods contained more seeds than June pods $(8.8 \pm$ 0.3 vs. $6.0 \pm 0.2$, respectively; $F=54.6, \mathrm{df}=1$, $17, P<0.0001)$.

Table 3. Number of 'AU Golden' plants containing seed pods per $\mathrm{m}^{2}$, number of seed pods per plant, number of seeds per pod, and yield (kg/ha) counted 116 and $122 \mathrm{~d}$ post planting for the $27 \mathrm{Apr}$. and 26 June plantings, respectively. Sunn hemp was planted at low (11.2 kg/ha) (SH11) or high (44.8 kg/ha) (SH44) seeding rates with (SH11SSG and SH44SSG) or without the addition of sorghum-sudangrass at $22.4 \mathrm{~kg} / \mathrm{ha}$ Citra, FL, 2015. Means within each variable and planting date followed by the same letter are not significantly different.

\begin{tabular}{|c|c|c|c|}
\hline Variable & Planting date & Treatment & Mean \pm SE \\
\hline \multirow[t]{8}{*}{ Plants with seed pods ${ }^{2}$} & 27 Apr. & SH11 & $11.3 \pm 3.8 \mathrm{a}$ \\
\hline & & SH11SSG & $27.7 \pm 13.7 \mathrm{a}$ \\
\hline & & SH44 & $14.7 \pm 5.6 \mathrm{a}$ \\
\hline & & SH44SSG & $36.7 \pm 15.1 \mathrm{a}$ \\
\hline & 26 June & SH11 & $18.3 \pm 2.9 \mathrm{ab}$ \\
\hline & & SH11SSG & $15.7 \pm 5.8 \mathrm{~b}$ \\
\hline & & SH44 & $40.3 \pm 7.2 \mathrm{a}$ \\
\hline & & SH44SSG & $33.3 \pm 7.7 \mathrm{ab}$ \\
\hline \multirow[t]{8}{*}{ Seed pods per plant ${ }^{y}$} & 27 Apr. & SH11 & $43.8 \pm 8.6 \mathrm{a}$ \\
\hline & & SH11SSG & $43.2 \pm 14.7 \mathrm{a}$ \\
\hline & & SH44 & $59.4 \pm 19.2 \mathrm{a}$ \\
\hline & & SH44SSG & $20.8 \pm 9.9 \mathrm{a}$ \\
\hline & 26 June & SH11 & $5.6 \pm 0.7 \mathrm{a}$ \\
\hline & & SH11SSG & $4.7 \pm 1.0 \mathrm{ab}$ \\
\hline & & SH44 & $2.4 \pm 0.3 b$ \\
\hline & & SH44SSG & $2.8 \pm 0.09 \mathrm{~b}$ \\
\hline \multirow[t]{8}{*}{ Seeds per pod ${ }^{\mathrm{x}}$} & 27 Apr. & SH11 & $9.85 \pm 0.3 \mathrm{a}$ \\
\hline & & SH11SSG & $8.67 \pm 0.4 \mathrm{a}$ \\
\hline & & SH44 & $8.64 \pm 0.5 \mathrm{a}$ \\
\hline & & SH44SSG & $8.0 \pm 1.1 \mathrm{a}$ \\
\hline & 26 June & SH11 & $6.61 \pm 0.3 \mathrm{a}$ \\
\hline & & SH11SSG & $6.06 \pm 0.5 \mathrm{a}$ \\
\hline & & SH44 & $5.34 \pm 0.5 \mathrm{a}$ \\
\hline & & SH44SSG & $6.0 \pm 0.04 \mathrm{a}$ \\
\hline \multirow[t]{8}{*}{ Yield $^{\mathrm{w}}$} & 27 Apr. & SH11 & $242.0 \pm 14.0 \mathrm{a}$ \\
\hline & & SH11SSG & $398.1 \pm 47.1 \mathrm{a}$ \\
\hline & & SH44 & $332.2 \pm 82.3 \mathrm{a}$ \\
\hline & & SH44SSG & $207.2 \pm 44.2 \mathrm{a}$ \\
\hline & 26 June & SH11 & $37.5 \pm 2.2 \mathrm{a}$ \\
\hline & & SH11SSG & $21.4 \pm 0.8 \mathrm{a}$ \\
\hline & & SH44 & $29.3 \pm 7.2 \mathrm{a}$ \\
\hline & & SH44SSG & $32.2 \pm 7.2 \mathrm{a}$ \\
\hline
\end{tabular}

${ }^{\mathrm{z}}$ Data were transformed using $\mathrm{Y}^{0.25}$. April, $F=0.93, \mathrm{df}=3,6, P=0.4811 ;$ June, $F=5.4, \mathrm{df}=3,6, P=$ 0.0383 .

${ }^{\mathrm{y}}$ Data were transformed using $\mathrm{Y}^{-0.25}$. April, $F=1.3 \mathrm{df}=3,6, P=0.3487$; June, $F=7.5, \mathrm{df}=3,6, P=$ 0.0187 .

${ }^{\mathrm{x}}$ Data were transformed using $\mathrm{Y}^{0.25}$. April, $F=1.4, \mathrm{df}=3,6, P=0.3302 ;$ June, $F=2.4, \mathrm{df}=3,6, P=0.1676$.

${ }^{\mathrm{w}}$ Data were transformed using $\log (\mathrm{Y})$. April, $F=2.6, \mathrm{df}=3,6, P=0.1497$; June, $F=3.3$, df = 3, 6, $P=$ 0.0979 . 
The addition of SSG to the sunn hemp cover crop had no deleterious effects on sunn hemp development based on plant density of seed yield. Plots planted at the high seeding rate plus SSG contained more sunn hemp plants than the low seeding rate plots with or without SSG (SH44SSG $33.5 \pm 3.0$, SH11SSG $18.1 \pm 2.5$, SH11 $12.2 \pm 2.0 ; F=$ $31.7, \mathrm{df}=3,24, P<0.0001)$. The addition of SSG plants in the plots did not influence the number of seed pods produced or the number of seeds per pod for either the April or June planting (Table 3).

\section{Discussion}

'AU Golden' was selected for its ability to flower and produce seed in Alabama because the previous commercial cultivar Tropic Sun does not (Mosjidis, 2014). Cho et al. (2016) attribute this to 'AU Golden' being derived from a day-neutral sunn hemp accession (PI 322377) whereas 'Tropic Sun' is a short-day cultivar. Our results demonstrate that these characteristics also apply to the environmental conditions found in north-central Florida, especially when planted in late April. In fact, our seed production in some plots of more than $400 \mathrm{~kg} / \mathrm{ha}$ was equivalent to yields in studies in Alabama $\left(32^{\circ} \mathrm{N}\right.$, $\approx 333 \mathrm{~km}$ north of our study) (Mosjidis, 2014). In 2014, 'Tropic Sun' and the unknown variety from South Africa produced very few flowers and no seed pods. Tillage Sunn produced flowers, but late in the season (October) as the experiment was being completed. Seed production has been demonstrated with the unknown variety from South Africa at a site above $30^{\circ} \mathrm{N}$, but again very late in the season (November, R.L. Meagher, unpublished data).

Planting sunn hemp at low seeding rates has been shown to increase branching and flower production with cultivars that display short daylength flowering (Abdul-Baki et al., 2001; Cho et al., 2015). Our results over 2 years with a cultivar that flowers earlier in the season were mixed. While the numbers of racemes, flowers, and seed pods can be affected by seeding rates, there is also evidence of the influence of seasonality as April plantings substantially differed in the relative numbers of plants with seed pods and number of seed pods per plant (Table 3). The overall results suggest that seed yield is a complex trait of which seeding rate may be a contributing but not a primary factor.

Earlier research in northern Florida suggested that the lack of seed production in late-blooming sunn hemp was because of pollinators not being active at the time of flowering (Cho et al., 2015). They suggested that large bees, such as carpenter bees (Xylocopa spp.) and leafcutting bees (Megachile spp.), should be able to pollinate the sunn hemp flowers. However, they were unable to obtain pod-set when they tested commercially available bumblebees (Bombus impatiens Cresson). Because we worked with a cultivar that flowered much earlier in the season, we were able to identify some of the species that visited sunn hemp flowers in north-central Florida (R.L. Meagher, unpublished data).

In summary, our research showed that planting 'AU Golden' earlier in the season and at a lower seeding rate promotes more branching and flower production, achieving seed set and seed production. Although all four of the sunn hemp lines we planted eventually flowered, only the day-neutral cultivar 'AU Golden' flowered early enough to produce a seed crop in north-central Florida. Current prices for $22.7 \mathrm{~kg}(50 \mathrm{lb})$ bags of sunn hemp seed range from $\$ 3.00 / \mathrm{kg}$ for Tillage Sunn to $\$ 3.96 / \mathrm{kg}$ for 'AU Golden'. Distributors sell foreign-grown varieties of sunn hemp for $\$ 3.00$ to $\$ 4.00 / \mathrm{kg}$. Most shipping from these U.S. distributors is free or $\$ 25-\$ 35$, depending on the distributor. Interestingly, 'Tropic Sun' is more difficult to get and is relatively expensive because it is grown and shipped from Hawaii $(\$ 8.70 / \mathrm{kg}$ with shipping at $\$ 90$ for a $22.7 \mathrm{~kg}$ bag). Therefore, the costs per ha for three sunn hemp lines used in this study at the high seeding rate are $\$ 134.40$ (Tillage Sunn), $\$ 177.41$ ('AU Golden'), and \$389.76 ('Tropic Sun'). The addition of SSG was done to add plant biomass to the plots. This relatively lower priced cover crop $(\$ 1.06-$ $\$ 3.22 / \mathrm{kg}$; $\$ 23.74-\$ 72.13 / \mathrm{ha}$ ) can be added to grower fields planted with a low seeding rate of 'AU Golden' sunn hemp to achieve benefits such as improving soil nutrition and promoting pollinators in agricultural landscapes.

\section{Literature Cited}

Abdul-Baki, A.A., H.H. Bryan, G.M. Zinati, W. Klassen, M. Codallo, and N. Heckert. 2001. Biomass yield and flower production in sunn hemp: Effect of cutting the main stem. J. Veg. Crop Prod. 7:83-104.

Adler, M.J. and C.A. Chase. 2007. Comparison of the allelopathic potential of leguminous summer cover crops: Cowpea, sunn hemp, and velvetbean. HortScience 42:289-293.

Bhan, M., R. McSorley, and C.A. Chase. 2010. Effect of cropping system complexity on plantparasitic nematodes associated with organically grown vegetables in Florida. Nematropica 40:53-70.

Braz, G.B.P., R.S. Oliveira, Jr., W.T. Crow, and C.A. Chase. 2016. Susceptibility of different accessions of Crotalaria juncea to Belonolaimus longicaudatus. Nematropica 46:3137.

Campbell, J.W., A. Irvin, H. Irvin, C. StanleyStahr, and J.D. Ellis. 2016. Insect visitors to flowering buckwheat, Fagopyrum esculentum (Polygonales: Polygonaceae), in northcentral Florida. Fla. Entomol. 99:264-268.

Cherr, C.M., J.M.S. Scholberg, and R. McSorley. 2006. Green manure as nitrogen source for sweet corn in a warm-temperature environment. Agron. J. 98:1173-1180.

Cherr, C.M., J.M.S. Scholberg, R. McSorley, and O.S. Mbuya. 2007. Growth and yield of sweet corn following green manure in a warm temperature environment on sandy soil. J. Agron. Crop Sci. 193:1-9.
Cho, A.H., C.A. Chase, D.D. Treadwell, R.L. Koenig, J.B. Morris, and J.P. MoralesPayan. 2015. Apical dominance and planting density effects on weed suppression by sunn hemp (Crotalaria juncea L.). HortScience 50:263-267.

Cho, A.H., C.A. Chase, R.L. Koenig, D.D. Treadwell, J. Gaskins, J.B. Morris, and J.P. Morales-Payan. 2016. Phenotypic characterization of 16 accessions of sunn hemp in Florida. Agron. J. 108:2417-2424.

Collins, A.S., C.A. Chase, W.M. Stall, and C.M. Hutchinson. 2008. Optimum densities of three leguminous cover crops for suppression of smooth pigweed (Amaranthus hybridus). Weed Sci. 56:753-761.

Ellis, K.E. and M.E. Barbercheck. 2015. Management of overwintering cover crops influences floral resources and visitation by native bees. Environ. Entomol. 44:9991010.

Elwakil, W.M. and M. Mossler. 2016. Florida crop/pest management profile: Cabbage. Univ. of Florida, IFAS Extension, CIR $1256,18 \mathrm{p}$

Javaid, M.M., M. Bhan, J.V. Johnson, B. Rathinasabapathi, and C.A. Chase. 2015. Biological and chemical characterizations of allelopathic potential of diverse accessions of the cover crop sunn hemp. J. Amer. Soc. Hort. Sci. 140:532-541.

Mansoer, Z., D.W. Reeves, and C.W. Wood. 1997. Suitability of sunn hemp as an alternative late-summer legume cover crop. Soil Sci. Soc. Amer. J. 61:246-253.

Meagher, R.L., R.N. Nagoshi, C. Stuhl, and E.R. Mitchell. 2004. Larval development of fall armyworm (Lepidoptera: Noctuidae) on different cover crop plants. Fla. Entomol. 87:454460.

Morris, J.B., C.A. Chase, D. Treadwell, R. Koenig, A. Cho, J.P. Morales-Payan, T. Murphy, and G.F. Antonious. 2015. Effect of sunn hemp (Crotalaria juncea L.) cutting date and planting density on weed suppression in Georgia, USA. J. Environ. Sci. Health B 50:614-621.

Mosjidis, J.A. 2007. Breeding of annual and perennial legumes and their utilization as forage and crops. Field Veg. Crops Res. 44:7-11.

Mosjidis, J.A. 2014. Sunn hemp cultivars capable of producing seed within the continental United States. United States Patent, US 8,680,369 B2.

Mosjidis, J.A. and G. Wehtje. 2011. Weed control in sunn hemp and its ability to suppress weed growth. Crop Prot. 30:7073.

Osborne, J. 2010. Improving your data transformations: Applying the Box-Cox transformation. Pract. Assess., Res. Eval. 15(12): $<$ http:// pareonline.net/getvn.asp? $\mathrm{v}=15 \& \mathrm{n}=12>$.

Pair, S.D. and J.K. Westbrook. 1995. Agroecological and climatological factors potentially influencing armyworm populations and their movement in the southeastern United States. Southwest. Entomol. 18: 101-118.

Riedinger, V., M. Renner, M. Rundlöf, I. Steffan-Dewenter, and A. Holzschuh. 2014. Early mass-flowering crops mitigate pollinator dilution in late-flowering crops. Landsc. Ecol. 29:425-435.

Rotar, P.R. and R.J. Joy. 1983. 'Tropic Sun' sunn hemp Crotalaria juncea L. Hawaii Institute of Tropical Agriculture and Human Resources, University of Hawaii at Manoa, 
Honolulu, HI. 7 pp. Research Extension Series 036. <http://www.ctahr.hawaii.edu/ oc/freepubs/pdf/RES-036.pdf $>$.

SAS Institute. 2012. SAS for Windows, 9.4.

Saunders, M.E., G.W. Luck, and M.M. Mayfield. 2013. Almond orchards with living ground cover host more wild insect pollinators. J. Insect Conserv. 17:1011-1025.
USDA-NASS. 2014. Census of agriculture. 25 Aug. 2016. <https://agcensus.usda.gov./Publications/ 2012/Full_Report/Volume_1,_Chapter_2 County_Level/Florida/st12_2_029_029.pdf $>$.

Wang, Q., W. Klassen, Y. Li, M. Codallo, and A.A. Abdul-Baki. 2005. Influence of cover crops and irrigation rates on tomato yields and quality in a subtropical region. HortScience 40:2125-2131.
Wang, M.L., J.A. Mosjidis, J.B. Morris, R.E. Dean, T.M. Jenkins, and G.A. Pederson. 2006. Genetic diversity of Crotalaria germplasm assessed through phylogenetic analysis of EST-SSR markers. Genome 49:707-771.

White, G.A. and J.R. Haun. 1965. Growing Crotalaria juncea, a multi-purpose legume, for paper pulp. Econ. Bot. 19:175-183. 